\title{
Wood Dust Exposure and Risk of Lung Cancer
}

\author{
Parveen Bhatti ${ }^{1}$, Laura Newcomer ${ }^{1}$, Lynn Onstad ${ }^{1}$, Kay Teschke $^{2}$, Janice Camp ${ }^{3}$, Michael \\ Morgan $^{3}$, and Thomas L. Vaughan ${ }^{1}$ \\ ${ }^{1}$ Program in Epidemiology, Division of Public Health Sciences, Fred Hutchinson Cancer Research \\ Center, Seattle, WA, USA \\ ${ }^{2}$ School of Environmental Health, University of British Columbia, Vancouver, BC, Canada \\ ${ }^{3}$ Department of Environmental and Occupational Health Sciences, School of Public Health, \\ University of Washington, Seattle, WA, USA
}

\begin{abstract}
Objectives-Despite the compelling association between wood dust and sinonasal cancer, there has been little systematic and rigorous study of the relationship between wood dust and lung cancer. We investigated whether a history of exposure to wood dust through occupational and hobby-related activities was associated with increased lung cancer risk.
\end{abstract}

Methods-We conducted a population-based case-control study, with 440 cases, identified from 1993 to 1996 through the Fred Hutchinson Cancer Research Center Cancer Surveillance System for western Washington State, and 845 age-matched controls, identified by random-digit dialing. Using detailed work and personal histories, quantitative estimates of cumulative exposure to wood dust (thought to be primarily from softwood) were calculated for each participant. Using unconditional logistic regression adjusted for age and smoking status, risk of lung cancer was examined in relation to employment in wood-related occupations, working with wood as a hobby, as well as cumulative wood dust exposure that took into account both occupational and hobbyrelated sources.

Results-While we observed an increased risk of lung cancer associated with working in a sawmill (OR=1.5; 95\% CI: 1.1, 2.1), we found no evidence of increased risks with other occupations, working with wood as a hobby or with estimated cumulative exposure to wood dust $(\mathrm{OR}=0.9 ; 95 \% \mathrm{CI}: 0.6,1.3$, for highest compared to lowest quartile of exposure). Contrary to our hypothesis, we observed modest non-significant decreased risks with exposure to wood dust, although no dose-response relationship was apparent.

Conclusions-This study provided somewhat reassuring evidence that softwood dust does not increase the risk of lung cancer, but future studies should closely evaluate exposure to hardwood dusts. Suggestive evidence for an inverse association may be attributable to the presence of

\footnotetext{
${ }^{*}$ Correspondence and reprint requests to: Parveen Bhatti, Program in Epidemiology, Division of Public Health Sciences, Fred Hutchinson Cancer Research Center, Seattle, WA, USA, TEL: 206-667-7803, FAX: 206-667-4787, pbhatti@fhcrc.org.

Competing Interests

None.

Ethics approval

The study was approved by the Fred Hutchinson Cancer Research Center Institutional Review Board.

Exclusive License

The Corresponding Author has the right to grant on behalf of all authors and does grant on behalf of all authors, an exclusive licence (or non-exclusive for government employees) on a worldwide basis to the BMJ Publishing Group Ltd and its Licensees to permit this article (if accepted) to be published in Occupational and Environmental Medicine and any other BMJPGL products to exploit all subsidiary rights, as set out in our licence.
} 
endotoxin in the wood dust, but the lack of a dose-response relationship suggests a non-causal relationship.

\section{Introduction}

Dust from the processing of wood is one of the more commonly encountered hazardous agents. More than 600,000 persons in the US are occupationally exposed on a regular basis, and many more come in contact with wood dust through hobbies ${ }^{1}$. Operations performed on wood can create dust in two ways: by shattering wood cells and by chipping out whole cells ${ }^{2}$. Shattering, which occurs almost exclusively during sanding operations, for example, results in a finer particle size and higher dust concentration than does chipping, which is more likely to occur in sawing and milling operations ${ }^{34}$. However, it is clear from industrial hygiene sampling that dust particles of respirable size are produced from even the coarsest wood processing activities ${ }^{4}$.

Clinical observations in the 1960s in the High Wycombe area near Oxford, England suggested that workers involved in the manufacture of furniture from hardwoods experienced substantially increased risks of sinonasal adenocarcinoma ${ }^{5}$, later estimated to be approximately 500-fold compared to the general population ${ }^{6}$. A subsequent study of this cancer occurring in England and Wales outside of the Oxford area confirmed a high relative risk $(\mathrm{RR}=95)$ nationwide for adenocarcinoma among furniture workers and also observed a five-fold relative risk among other woodworkers, principally carpenters and joiners, compared to the general population ${ }^{7}$. While sinonasal cancer (SNC) has been clearly associated with hardwood dust, increased risks with softwood dust have not been ruled out ${ }^{1}$. For instance, a recent study of occupation and cancer among 15 million people in five Nordic countries found that SNC risk was increased among workers that were exclusively exposed to softwood dust ${ }^{8}$. Furthermore, studies in cell lines have shown both hardwood and softwood dusts to induce inflammation responses, generate reactive oxygen species and induce DNA damage ${ }^{9-11}$, all of which are recognized as important mechanisms in carcinogenesis.

Wood dust has long been recognized as a respiratory irritant with studies of dust from certain tree species demonstrating adverse effects on the lung, including asthma, chronic obstructive pulmonary disease, decline in lung function over the workshift, and decreased forced vital capacity, among woodworkers in a variety of jobs ${ }^{12-14}$. Results of studies examining associations between wood dust and lung cancer, however, have been inconclusive ${ }^{115-21}$, which may be attributable to the relatively crude exposure assessments that have been used in many of these studies. Thus, the aim of the present case-control study was to investigate the possible association between wood dust exposure and lung cancer, with individual quantitative estimates of wood dust exposure, in the more rural areas of Washington State where work in wood-related industries and wood-related hobbies are common $^{22-24}$.

\section{Methods}

Procedures for this study were approved by the Fred Hutchinson Cancer Research Center Institutional Review Board, and all participating subjects provided informed consent.

\section{Identification of cases and controls}

Cases were prospectively identified through rapid reporting mechanisms of the Fred Hutchinson Cancer Research Center's Cancer Surveillance System, a population-based registry that operates as part of the Surveillance, Epidemiology and End Results program of the National Cancer Institute. Eligible cases included all men who were newly diagnosed 
with lung cancer between 5/1/1993 and 7/31/1996 and who, at the time of diagnosis, were between 18 and 74 years of age and resided in an eleven-county area of western Washington, where work in wood related industries is most common. The two most populous counties that include the cities of Seattle and Tacoma were excluded because wood-related occupations were expected to be rare in these areas. All eligible cases were selected for the study with the exception of those who were 70-74 years of age at diagnosis, of whom 50\% were randomly selected; given the natural risk of lung cancer incidence with age, this was done to limit the relatively large number of older participants that may have had difficulty recalling details of their occupational history.

Controls were males identified between 1993 and 1996 from the same geographic area as the cases through random digit dialing, using a modified Waksberg's method ${ }^{25}$ and were frequency matched to cases by 5 -year age group. In this method, a representative sample of households in a geographic region is identified by the random generation of telephone numbers from lists of working exchanges. Each number is called up to nine times at different times of the day and week over a period of up to several months to find whether the number identifies a residence, and if so, whether an eligible control resides there.

\section{Data collection}

Experienced interviewers conducted structured telephone interviews with cases and controls. Of 929 eligible cases identified by the cancer registry, telephone interviews were successfully completed for $821(88.4 \%)$. To maintain comparability with controls, 37 cases without a telephone at the time of diagnosis were excluded, yielding 784 cases for the study. Clinical information regarding the cancer, including histological type and subsite, was determined from medical records by trained registry personnel.

In ascertaining controls, 8,129 residential phone numbers were identified, of which 7,870 (96.8\%) were successfully screened to determine if an eligible control resided in the household. A total of 1,047 eligible controls were identified and approached for interview, of which $883(84.3 \%)$ were successfully interviewed, yielding an overall control response rate of $81.6 \%$. Seven controls without a residential telephone one year before the interview were excluded, leaving 876 for the study.

If a subject died before the interview could be arranged, or was too ill, a proxy respondent (usually the wife) was interviewed. This occurred for 344 case and 31 control interviews. Given that proxies were unlikely to accurately recall detailed information regarding work histories, cases and controls requiring proxy respondents were excluded from the current analysis to minimize the impact of exposure misclassification. This left 440 cases and 845 controls for analysis.

All questions in the interview referred to the period before the reference date, which was one year before diagnosis for cases and one year before ascertainment for controls. Cases were interviewed a median of 129 days after diagnosis, while controls were interviewed a median of 48 days after ascertainment. We collected information on demographic background, previous medical conditions, family history of cancer, use of tobacco and alcohol products and a lifetime occupational and chemical exposure history. For each job that a respondent held for at least 6 months, we inquired about the job title, typical activities and duties in the job, the type of industry, and the start and stop dates.

The majority of the interview focused on specifics of employment in seven wood-related industries: logging, sawmills, plywood manufacturing, particle board manufacturing, pulp and paper mills, finish carpentry and general carpentry. For each industry in which a participant had worked, we enquired about involvement in processes specific to that industry 
which were known to usually entail significant exposure to wood dust. For each such process we collected information on the participant's usual activities related to the process, the duration and typical hours per day spent in such activities, and a number of potential modifiers of exposure. For example, for those who had worked in the plywood industry, we enquired about working near where the wood was sawn; where it was shaped (i.e. planed, routed or molded); where it was chipped; where it was sanded; and use of compressed air to clean dusty areas. For certain processes, e.g., sanding, we further enquired about distance from the wood dust source (the sander) and use of enclosed booths. A set of questions also focused on working with wood as a hobby, and collected data on duration and frequency of specific activities including sawing, sanding, and shaping; and the usual location (outdoors vs. indoors).

\section{Exposure assessment}

Estimation of exposure to wood dust was based on an algorithm that took into account the typical concentration specific to the occupational and hobby-related process involved and a number of modifiers of that concentration. The typical exposure levels and modifiers were based on a detailed review of the published industrial hygiene literature ${ }^{26-29}$, examination of databases containing representative measurements of wood dust concentrations linked with specific processes and field measurements carried out specifically for this study.

Wood dust data was requested from the Occupational Safety and Health Administration Integrated Management Information System (OHSA IMIS) for the period from its inception (May 1,1979 ) to July $31,1997^{30}$. The database included 1,632 measurements taken by state and federal inspection personnel and ancillary data about the industry, occupation, location of the work site, wood type and circumstances of measurement. Dust concentrations were measured using a non-specific "total" particulate technique ${ }^{31}$, though wood dust would be expected to predominate in these measurements.

Worksite sampling of 8-hour total wood dust concentrations targeted several industries for which we judged the existing literature and data were limited or unreliable, including the chip screening areas and chipping yards in the pulp and paper industry, the logging and yarding areas of the timber industry, and various operations of a door manufacturing and cabinet making plant. The purpose of these measurements was to estimate typical dust concentrations in occupations and industries judged to be less well represented in the OSHA database.

The processes considered, typical exposure levels for each process and applicable industries are listed in Table 1. Activities in the logging industry were judged not to entail significant wood dust exposures and were therefore not included in the estimates of exposure. Table 2 describes the modifiers of exposure that were assessed, the processes they were applicable to, and the appropriate multiplier associated with each factor level. For example, an operator of a power sander in the finish carpentry industry, who was typically within 1.5 meters of the tool, would be assigned a concentration of $19 \mathrm{mg} / \mathrm{m}^{3}$ for the exposure period $(100 \%$ of the unmitigated level); whereas someone who typically worked near $(1.5-3.0$ meters) a sanding operation would be assigned $30 \%$ of the typical exposure $\left(5.7 \mathrm{mg} / \mathrm{m}^{3}\right)$.

For each process, each individual's cumulative exposure to wood dust (in units of months$\mathrm{mg} / \mathrm{m}^{3}$ ) was calculated by summing the product of duration (months) working in or near the process, the proportion of a 40-hour work week typically spent in or near the process (this was calculated for hobbies as well), the average exposure intensity $\left(\mathrm{mg} / \mathrm{m}^{3}\right)$, and the modifying factors. 


\section{Statistical analyses}

RRs were estimated by calculation of odds ratios (ORs) and 95\% confidence intervals (CIs) using unconditional logistic regression models. We examined RR of lung cancer in relation to employment history in wood-related occupations and processes and history of woodrelated hobbies, as well as in relation to categories of cumulative wood dust exposure from individual occupational and hobby-related processes and to all processes combined. Quartiles of cumulative wood dust exposure were calculated based on the distribution of cumulative wood dust exposure among controls.

Age ( $\leq 39,40-49,50-59,60-69, \geq 70)$ and smoking status (never, former, current) were included as covariates in all models. Race, education and pack-years of smoking were also examined as potential confounding factors but did not have a material impact $(\geq 10 \%$ change) on the point estimates of interest so were not included in the final analyses. Analyses were repeated for specific histologic subtypes (carcinoma NOS, large cell, small cell, squamous, adenocarcinoma, other). Possible interactions between smoking and wood dust exposure were examined by stratum-specific analyses, and by evaluating interaction terms in the logistic model.

\section{Results}

Demographic characteristics of the cases and controls are summarized in Table 3. Cases and controls were quite similar in age distribution, with mean ages of 61.8 and 61.1 years, respectively. Over $95 \%$ of subjects were classified as Caucasian, with controls reporting more years of education than cases. As expected, a larger proportion of cases were current smokers and had greater pack years of smoking than controls. In terms of general work history, controls tended to report working a greater number of jobs than cases; however cases and controls reported similar total years worked and ages at first job. For cases, histologic classification and disease stage are also listed in Table 3. The most common histologic groups were adenocarcinoma, squamous cell and small cell carcinoma.

Table 4 describes the history of working in wood-related jobs and hobbies in lung cancer cases and controls. There was statistically significant evidence of an increased risk of lung cancer among those reporting working in sawmills, whereas working as a general carpenter and working with wood as a hobby were associated with modestly, but significantly, decreased risks. Working in a plant that manufactured plywood, in a plant that manufactured particle board and in a pulp and paper mill were also associated (non-significantly) with modestly decreased risks.

The distribution of estimates of cumulative exposure to wood dust from all sources and from each primary process are summarized in Table 5. Overall there was no evidence of increased lung cancer risk associated with cumulative exposure to wood dust. Many of the RR estimates were below unity, although none were statistically significant, and no doseresponse was evident. Stratification by histological type or smoking status did not produce markedly different results (not shown).

\section{Discussion}

In this population-based case-control study, we found no evidence of increased risk of lung cancer when evaluating wood dust exposure in occupational and hobby-related settings in Washington State. In fact, contrary to our hypothesis, we observed slightly decreased risks with exposure to wood dust in most specific processes as well as overall. However, most of the effect estimates were not statistically significant, and no dose-response relationship was apparent. We also observed very little evidence of increased risk associated with specific 
wood-related jobs or working with wood as a hobby, with the exception of a 50\% increased risk associated with working in a sawmill.

Of the 24 lung cancer case-control studies reviewed by IARC ${ }^{1}$ (no cohort studies were identified), only seven specifically assessed exposure to wood dust. Of these, four studies provided evidence of slightly increased risks. The inconsistent findings and lack of exposure-response relationships led the IARC Working Group to conclude that there was no indication of a role for occupational exposure to wood dust in the causation of lung cancer. More recent studies have also produced mixed results, but, unlike our study, a lack of data accounting for intensity, frequency and duration of exposure to wood dust has been a major limitation of these studies ${ }^{15-21}$.

Over a six year follow-up in the American Cancer Society Prevention Study-II, there was an increased risk of lung cancer among men reporting exposure to wood dust [OR $=1.2$ (95\% CI: 1.0, 1.3) $]^{21}$. However, there was no evidence of an increasing risk of lung cancer with increasing duration of exposure except when the analysis was restricted to woodworkers. A large US based case-control study (1,368 cases, 1,192 controls) found that a history of work in a wood dust-related occupation or industry (based on self-reported longest employment in a wood related occupation or industry, or self-reported exposure to wood dust from a list of substances) was associated with an increased risk of lung cancer [OR $=3.2$ (95\% CI: 1.5 , 6.9) $]^{17}$. Similar risks were observed across the various histologic subtypes and there was evidence of a trend with increasing years of employment in these occupations or industries and evidence of an increased effect with smoking. In another US based case-control study (809 cases, 1,522 controls), individuals reporting 20 or more years of "regular" exposure to occupational wood dust were at an increased risk of developing lung cancer [OR $=2.2(95 \%$ CI: $1.3,3.6)]^{19}$. Similar risks were seen across the various histologic subtypes, except for large cell lung cancer. There was also suggestive evidence of effect modification by smoking status, with increased risks of wood-dust related lung cancer observed among smokers but not among non-smokers. While the exposure assessment accounted for frequency, respondents were asked to report it as "usually", "occasionally", "never" or "don't know" without any definition of the categories. In a cohort study of furniture workers in Estonia, there was no evidence of increased incidence of lung cancer compared to the general population ${ }^{18}$, and an increased risk was not observed when evaluating "moderate" or "high" exposure jobs or when considering various durations of employment. A recent occupational cohort study used a job-exposure matrix to evaluate cumulative exposure to a variety of organic dusts and also found no evidence of increased lung cancer risk with increasing exposure to wood dust ${ }^{20}$. While the study used quantitative exposure data, exposure levels were assigned based on job titles rather than subject specific occupational histories.

Strengths of the present study include its population-based design, the large sample size based in a geographic area with a relatively large concentration of wood workers and detailed exposure assessment that included field measurements. We were able to account for the intensity, frequency and duration of exposure to various occupational sources of wood dust, which has been a major limitation of previous studies.

A limitation of our study is that exposure estimates were based on recalled occupational histories and working conditions. Differential recall may explain controls reporting a greater number of jobs than cases, and thus the protective effects of exposure that were observed. However, cases and controls reported similar numbers of years worked and ages at first job, and because exposures were not assigned based on self-reported wood dust exposures, but rather the specific job and tasks performed by participants were assigned exposures via an objective protocol, recall bias is less likely. Residual confounding from incomplete 
adjustment for smoking may be a concern; however, this is unlikely to explain the observed protective effects since smoking status and pack years were found to be uncorrelated with cumulative wood dust exposure. Another limitation is that a large number of cases could not be interviewed directly because they had died or were too ill. Though we obtained work history data from proxy respondents for these cases, we excluded them from analysis to minimize the impact of exposure misclassification. While our results may be biased if exposure levels for the excluded cases were systematically different, these two groups of cases were not significantly different in terms age, race, smoking history and cancer histology (results not shown). Cases with proxy respondents were, however, more likely to be diagnosed with disease of a distant stage (66\%) as compared to directly interviewed cases $(33 \%)$.

While epidemiologic studies have more clearly established the carcinogenicity of hardwood dust (in association with sino-nasal cancer) than that for softwood dust, recent studies in cell-lines have shown softwood dusts to induce carcinogenic mechanisms such as inflammation, production of reactive oxygen species and DNA damage in cell-lines ${ }^{9-11}$. Nonetheless, a limitation of this study, as with many others, is the lack of data on wood types that participants worked with. In Washington softwoods are primarily used in industrial activities; however, exposure to hardwood dust cannot be ruled out. We were also unable to account for differences in the fraction of respirable dusts between the various processes, since exposure estimates were based on measurements of total dust. However, no major differences were observed in effect estimates when stratified by process type.

The suggestive evidence of an inverse association, in part, may be attributable to the presence of endotoxin in wood dust ${ }^{32}$, exposure to which has been observed in sawmills and joineries ${ }^{3334}$. Endotoxin has been associated with a decreased risk of lung cancer in other occupational settings, particularly the textile industry ${ }^{3536}$. Interestingly, while a recent study among Shanghai textile workers found decreased risks of lung cancer attributable to endotoxin ${ }^{35}$, a report from the same cohort found increased risks of $\mathrm{SNC}^{37}$, making an inverse association of lung cancer with wood dust exposure somewhat plausible. However, because we observed an increased risk of lung cancer among sawmill workers and did not observe a relationship of decreasing lung cancer risk with increasing wood dust exposure, this suggests the absence of a protective effect. Furthermore, exposures to endotoxin among woodworkers are much lower than those observed for textile workers. For example, assuming that 1 ng of endotoxin is equivalent to 10 endotoxin units $(\mathrm{EU})^{38}$, the geometric mean of inhalable endotoxin measured during a 6 to 8 hour work shift across various sawmills and joineries in Australia ranged from 3.7 to $91.1 \mathrm{EU} / \mathrm{m}^{334}$. Across various processes in three textile factories in Shanghai, the geometric mean of inhalable endotoxin measured during half-shift periods ranged from 40.3 to $2079.2 \mathrm{EU} / \mathrm{m}^{3} 35$.

Overall, we did not observe an increased risk of lung cancer with increased exposure to wood dust. Rather, we found suggestive evidence that wood dust exposure was associated with a decreased risk of lung cancer. A protective effect has not been observed in previous studies, but exposure assessment in many of these studies was a major limitation. The lack of a dose-response relationship with cumulative exposure suggests a non-causal relationship, but future studies exploring the possible role of exposure to endotoxin in wood dust in the etiology of lung cancer may be fruitful.

\section{What this paper adds:}

- Results from previous studies of occupational wood dust exposure and lung cancer have been mixed. 
- We constructed an exposure metric that accounted for intensity, frequency and duration of exposure to wood dust based on detailed work history data.

- We found suggestive evidence of an inverse association between wood dust and lung cancer risk.

- This study provides somewhat reassuring evidence that softwood dust does not increase the risk of lung cancer.

\section{Acknowledgments}

Funding

Support for this research was provided by grant R01CA53392 from the National Cancer Institute (USA).

\section{References}

1. IARC Working Group on the Evaluation of Carcinogenic Risks to Humans. Wood dust and formaldehyde. Lyon: World Health Organization, International Agency for Research on Cancer; 1995. International Agency for Research on Cancer.

2. Hinds WC. Basis for particle size-selective sampling for wood dust. Applied Industrial Hygiene. 1988; 3:67-72.

3. Scheeper B, Kromhout H, Boleij JS. Wood-dust exposure during wood-working processes. Ann Occup Hyg. 1995; 39:141-154. [PubMed: 7741413]

4. Teschke K, Demers PA, Davies HW, et al. Determinants of exposure to inhalable particulate, wood dust, resin acids, and monoterpenes in a lumber mill environment. Ann Occup Hyg. 1999; 43:247255. [PubMed: 10432869]

5. Macbeth R. Malignant Disease of the Paranasal Sinuses. J Laryngol Otol. 1965; 79:592-612. [PubMed: 14335138]

6. Acheson ED, Cowdell RH, Hadfield E, et al. Nasal cancer in woodworkers in the furniture industry. Br Med J. 1968; 2:587-596. [PubMed: 5654629]

7. Acheson ED, Cowdell RH, Rang E. Adenocarcinoma of the nasal cavity and sinuses in England and Wales. Br J Ind Med. 1972; 29:21-30. [PubMed: 5060244]

8. Pukkala E, Martinsen JI, Lynge E, et al. Occupation and cancer - follow-up of 15 million people in five Nordic countries. Acta Oncol. 2009; 48:646-790. [PubMed: 19925375]

9. Bornholdt J, Saber AT, Sharma AK, et al. Inflammatory response and genotoxicity of seven wood dusts in the human epithelial cell line A549. Mutat Res. 2007; 632:78-88. [PubMed: 17590384]

10. Maatta J, Luukkonen R, Husgafvel-Pursiainen K, et al. Comparison of hardwood and softwood dust-induced expression of cytokines and chemokines in mouse macrophage RAW 264.7 cells. Toxicology. 2006; 218:13-21. [PubMed: 16202497]

11. Pylkkanen L, Stockmann-Juvala H, Alenius H, et al. Wood dusts induce the production of reactive oxygen species and caspase-3 activity in human bronchial epithelial cells. Toxicology. 2009; 262:265-270. [PubMed: 19573573]

12. Carosso A, Ruffino C, Bugiani M. Respiratory diseases in wood workers. Br J Ind Med. 1987; 44:53-56. [PubMed: 3814535]

13. Holmstrom M, Wilhelmsson B. Respiratory symptoms and pathophysiological effects of occupational exposure to formaldehyde and wood dust. Scand J Work Environ Health. 1988; 14:306-311. [PubMed: 3201190]

14. Holness DL, Sass-Kortsak AM, Pilger CW, et al. Respiratory function and exposure-effect relationships in wood dust-exposed and control workers. J Occup Med. 1985; 27:501-506. [PubMed: 4032087]

15. Andersson E, Persson B, Bryngelsson IL, et al. Cancer mortality in a Swedish cohort of pulp and paper mill workers. Int Arch Occup Environ Health. 2010; 83:123-132. [PubMed: 19636585] 
16. Baran S, Teul I. Wood dust: an occupational hazard which increases the risk of respiratory disease. J Physiol Pharmacol. 2007; 58 Suppl 5:43-50. [PubMed: 18204114]

17. Barcenas CH, Delclos GL, El-Zein R, et al. Wood dust exposure and the association with lung cancer risk. Am J Ind Med. 2005; 47:349-357. [PubMed: 15776474]

18. Innos K, Rahu M, Rahu K, et al. Wood dust exposure and cancer incidence: a retrospective cohort study of furniture workers in Estonia. Am J Ind Med. 2000; 37:501-511. [PubMed: 10723044]

19. Jayaprakash V, Natarajan KK, Moysich KB, et al. Wood dust exposure and the risk of upper aerodigestive and respiratory cancers in males. Occup Environ Med. 2008; 65:647-654. [PubMed: 18182588]

20. Laakkonen A, Kyyronen P, Kauppinen T, et al. Occupational exposure to eight organic dusts and respiratory cancer among Finns. Occup Environ Med. 2006; 63:726-733. [PubMed: 16601013]

21. Stellman SD, Demers PA, Colin D, et al. Cancer mortality and wood dust exposure among participants in the American Cancer Society Cancer Prevention Study-II (CPS-II). Am J Ind Med. 1998; 34:229-237. [PubMed: 9698991]

22. Jackson LA, Wang SP, Nazar-Stewart V, et al. Association of Chlamydia pneumoniae immunoglobulin A seropositivity and risk of lung cancer. Cancer Epidemiol Biomarkers Prev. 2000; 9:1263-1266. [PubMed: 11097237]

23. Nazar-Stewart V, Vaughan TL, Stapleton P, et al. A population-based study of glutathione Stransferase M1, T1 and P1 genotypes and risk for lung cancer. Lung Cancer. 2003; 40:247-258. [PubMed: 12781423]

24. Sweeney C, Nazar-Stewart V, Stapleton PL, et al. Glutathione S-transferase M1, T1, and P1 polymorphisms and survival among lung cancer patients. Cancer Epidemiol Biomarkers Prev. 2003; 12:527-533. [PubMed: 12814998]

25. Waksberg J. Sampling Methods for Random Digit Dialing. Journal of the American Statistical Association. 1978; 73:40-46.

26. Hounam RF, Williams J. Levels of airborne dust in furniture making factories in the High Wycombe area. Br J Ind Med. 1974; 31:1-9. [PubMed: 4821408]

27. McCammon CS Jr, Robinson C, Waxweiler RJ, et al. Industrial hygiene characterization of automotive wood model shops. Am Ind Hyg Assoc J. 1985; 46:343-349. [PubMed: 3880187]

28. Sass-Kortsak AM, Holness DL, Pilger CW, et al. Wood dust and formaldehyde exposures in the cabinet-making industry. Am Ind Hyg Assoc J. 1986; 47:747-753. [PubMed: 3799474]

29. Whitehead LW, Freund T, Hahn LL. Suspended dust concentrations and size distribution and quantitative analysis of inorganic particles from woodworking operations. Am Ind Hyg Assoc J. 1981; 42:461-467.

30. Teschke K, Marion SA, Vaughan TL, et al. Exposures to wood dust in U.S. industries and occupations, 1979 to 1997. Am J Ind Med. 1999; 35:581-589. [PubMed: 10332511]

31. Health NIfOSa. , editor. NIOSH Manual of Analytical Methods. 1994. Method 0500, particulates not otherwise regulated, total.

32. Lenters V, Basinas I, Beane-Freeman L, et al. Endotoxin exposure and lung cancer risk: a systematic review and meta-analysis of the published literature on agriculture and cotton textile workers. Cancer Causes Control. 21:523-555. [PubMed: 20012774]

33. Dennekamp M, Demers P, Bartlett K, et al. Endotoxin exposure among softwood lumber mill workers in the Canadian province of British Columbia. Ann Agric Environ Med. 1999; 6:141-146. [PubMed: 10607995]

34. Mandryk J, Alwis KU, Hocking AD. Work-related symptoms and dose-response relationships for personal exposures and pulmonary function among woodworkers. Am J Ind Med. 1999; 35:481490. [PubMed: 10212701]

35. Astrakianakis G, Seixas N, Camp J, et al. Cotton dust and endotoxin levels in three Shanghai textile factories: a comparison of samplers. J Occup Environ Hyg. 2006; 3:418-427. [PubMed: 16862712]

36. Lundin JI, Checkoway H. Endotoxin and Cancer. Environmental Health Perpectives. 2009 in press.

37. Li W, Ray RM, Gao DL, et al. Occupational risk factors for nasopharyngeal cancer among female textile workers in Shanghai, China. Occup Environ Med. 2006; 63:39-44. [PubMed: 16361404] 
38. Mueller M, Lindner B, Kusumoto S, et al. Aggregates are the biologically active units of endotoxin. J Biol Chem. 2004; 279:26307-26313. [PubMed: 15096514] 


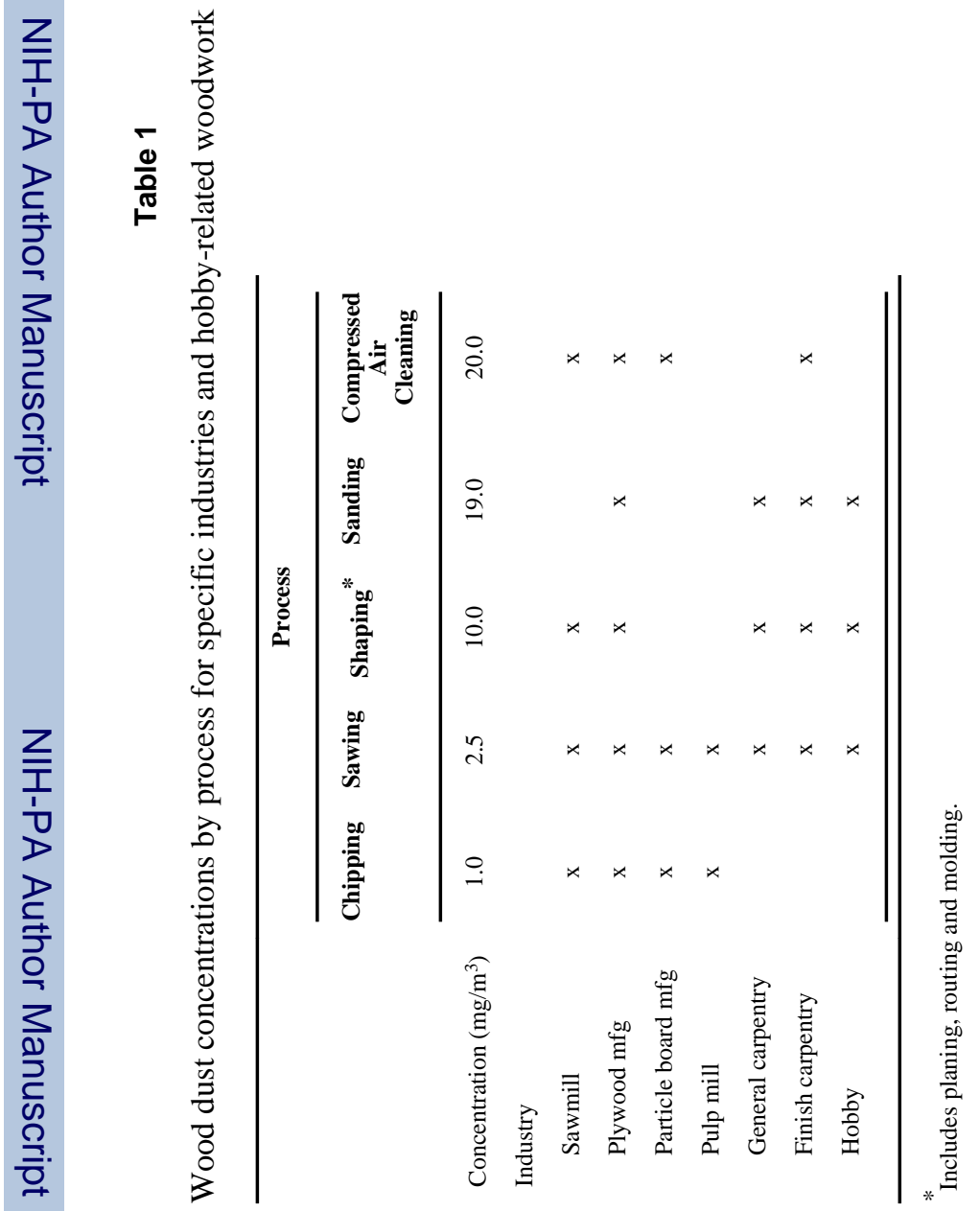


Table 2

Modifiers of wood dust concentration

\begin{tabular}{llcl}
\hline Modifier* $^{*}$ & Level & $\begin{array}{c}\text { Multiplication } \\
\text { Factor }\end{array}$ & Application Process \\
\hline Distance to blade or process (meters) & $0-<1.5$ & 1.00 & Sawing, Shaping, Chipping, Sanding \\
& $1.5-<3.0$ & 0.30 & \\
& $3.0-<6.0$ & 0.14 & \\
& $\geq 6.0$ & 0.10 & Sawing, Shaping, Chipping, Sanding \\
Enclosed booth & No & 1.00 & \\
& Yes & 0.05 & Sanding (general and finish carepentry, woodworking hobby) \\
Type of tool & Power & 1.00 & Sawing (woodworking hobby) \\
& Hand & 0.25 & Sawing, Sanding, Shaping (woodworking hobby) \\
\hline
\end{tabular}

Each modifier specific to certain operations 
Table 3

Demographic and disease characteristics of lung cancer cases and controls

\begin{tabular}{|c|c|c|c|c|}
\hline & \multicolumn{2}{|c|}{$\begin{array}{c}\text { Cases } \\
(\mathrm{N}=440)\end{array}$} & \multicolumn{2}{|c|}{$\begin{array}{l}\text { Controls } \\
(\mathrm{N}=845)\end{array}$} \\
\hline & $\mathbf{N}$ & $(\%)$ & $\mathbf{N}$ & $(\%)$ \\
\hline \multicolumn{5}{|l|}{ Age (years) } \\
\hline Age $\leq 39$ & 5 & $(0.6)$ & 25 & (3.0) \\
\hline Age $40-49$ & 42 & $(5.0)$ & 70 & $(8.3)$ \\
\hline Age $50-59$ & 116 & $(13.7)$ & 197 & (23.3) \\
\hline Age $60-69$ & 206 & $(24.4)$ & 402 & (47.6) \\
\hline Age $\geq 70$ & 71 & (8.4) & 151 & $(17.9)$ \\
\hline \multicolumn{5}{|l|}{ Race } \\
\hline Caucasian & 420 & $(95.5)$ & 815 & (96.5) \\
\hline African(American & 2 & $(0.5)$ & 3 & $(0.4)$ \\
\hline Asian & 2 & $(0.5)$ & 11 & $(1.3)$ \\
\hline Native American/Eskimo & 7 & (1.6) & 4 & $(0.5)$ \\
\hline Other & 9 & $(2.1)$ & 11 & $(1.3)$ \\
\hline Refused & 0 & (0) & 1 & $(0.1)$ \\
\hline \multicolumn{5}{|l|}{$\underline{\text { Smoking status }}$} \\
\hline Never & 13 & (3.0) & 243 & (28.8) \\
\hline Former & 162 & $(36.8)$ & 435 & $(51.5)$ \\
\hline Current & 265 & $(60.2)$ & 166 & (19.7) \\
\hline Missing & 0 & (0) & 1 & $(0.1)$ \\
\hline \multicolumn{5}{|l|}{$\underline{\text { Smoking pack years }}$} \\
\hline Never & 13 & (3.0) & 243 & (28.8) \\
\hline$>0-<20$ & 19 & (4.3) & 204 & $(24.1)$ \\
\hline $20-<40$ & 84 & $(19.1)$ & 193 & (22.8) \\
\hline $40-<60$ & 142 & $(32.3)$ & 107 & (12.7) \\
\hline $60-<80$ & 84 & $(19.1)$ & 44 & $(5.2)$ \\
\hline$\geq 80$ & 98 & $(22.3)$ & 54 & $(6.4)$ \\
\hline \multicolumn{5}{|l|}{ Education } \\
\hline$<$ High School & 94 & $(21.4)$ & 87 & $(10.3)$ \\
\hline High School /Vocational School Graduate & 182 & (41.4) & 290 & $(34.3)$ \\
\hline College & 163 & $(37.0)$ & 468 & $(55.4)$ \\
\hline Missing & 1 & $(0.2)$ & 0 & $(0)$ \\
\hline \multicolumn{5}{|l|}{$\underline{\text { Total number of jobs }}$} \\
\hline$<6$ & 121 & $(27.5)$ & 169 & (20.0) \\
\hline $6-7$ & 115 & (26.1) & 185 & (21.9) \\
\hline $8-10$ & 116 & (26.4) & 231 & (27.3) \\
\hline$\geq 11$ & 88 & $(20.0)$ & 260 & (30.8) \\
\hline \multicolumn{5}{|l|}{ Total years worked } \\
\hline$<35$ & 115 & (26.1) & 188 & (22.3) \\
\hline $35-<41$ & 111 & $(25.2)$ & 213 & (25.2) \\
\hline
\end{tabular}




\begin{tabular}{lrrrr}
\hline & \multicolumn{3}{c}{$\begin{array}{c}\text { Cases } \\
(\mathbf{N = 4 4 0})\end{array}$} & $\begin{array}{c}\text { Controls } \\
(\mathbf{N = 8 4 5})\end{array}$ \\
& $\mathbf{N}$ & $(\boldsymbol{\%})$ & $\mathbf{N}$ & $(\boldsymbol{\%})$ \\
\hline $41-<46$ & 110 & $(25.0)$ & 226 & $(26.8)$ \\
$>46$ & 104 & $(23.6)$ & 217 & $(25.7)$ \\
Age at first job & & & & \\
$\leq 16$ & 63 & $(14.3)$ & 114 & $(13.5)$ \\
17 & 265 & $(60.2)$ & 488 & $(57.8)$ \\
$\geq 18$ & 112 & $(25.2)$ & 242 & $(28.7)$ \\
Histology groupings & & & & \\
Carcinoma NOS & 57 & $(13.0)$ & & \\
Large Cell & 15 & $(3.4)$ & & \\
Small Cell & 85 & $(19.3)$ & & \\
Squamous & 124 & $(28.2)$ & & \\
Adenocarcinoma & 154 & $(35.0)$ & & \\
Other & 5 & $(1.1)$ & & \\
Stage & & & & \\
Local & 82 & $(18.6)$ & & \\
Regional & 176 & $(40.0)$ & & \\
Distant & 145 & $(33.0)$ & & \\
Unknown & 37 & $(8.4)$ & & \\
\hline
\end{tabular}




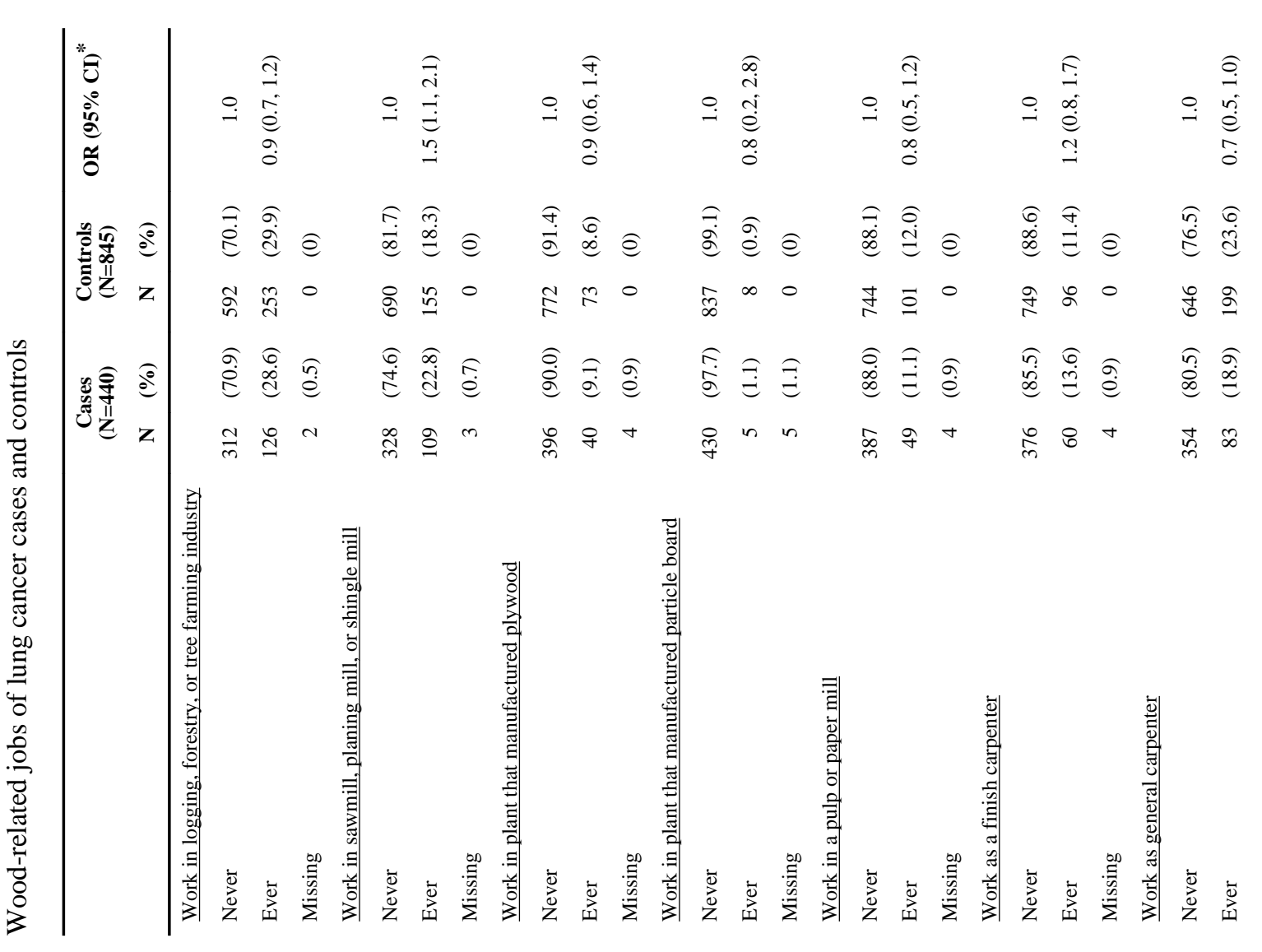


Bhatti et al.

Page 16

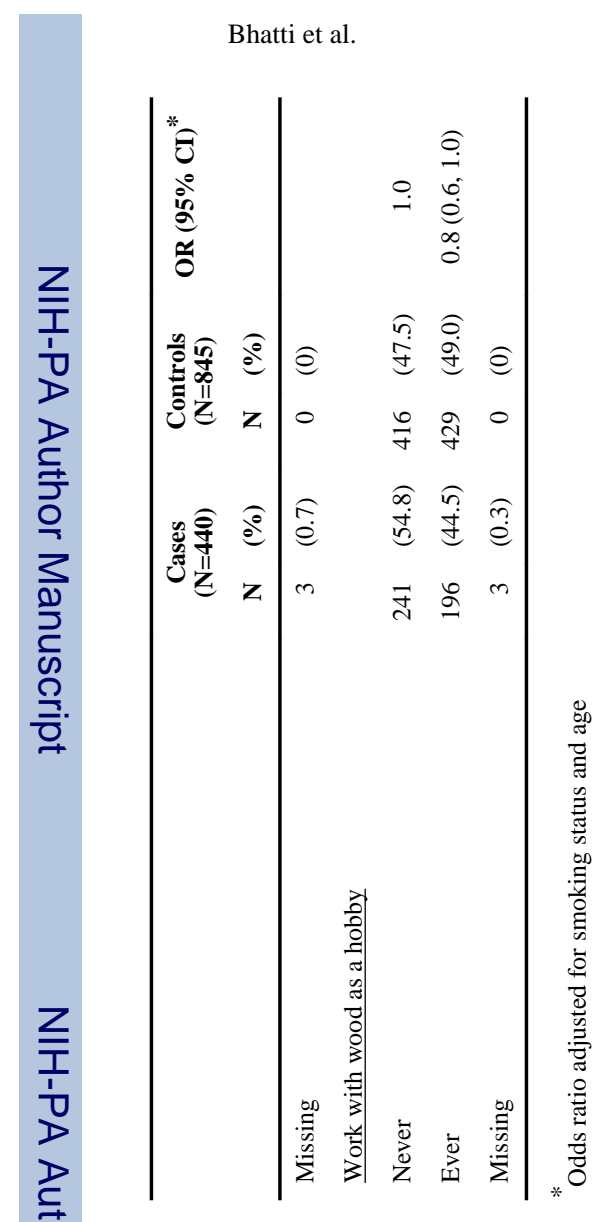

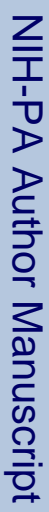

Occup Environ Med. Author manuscript; available in PMC 2012 August 1. 


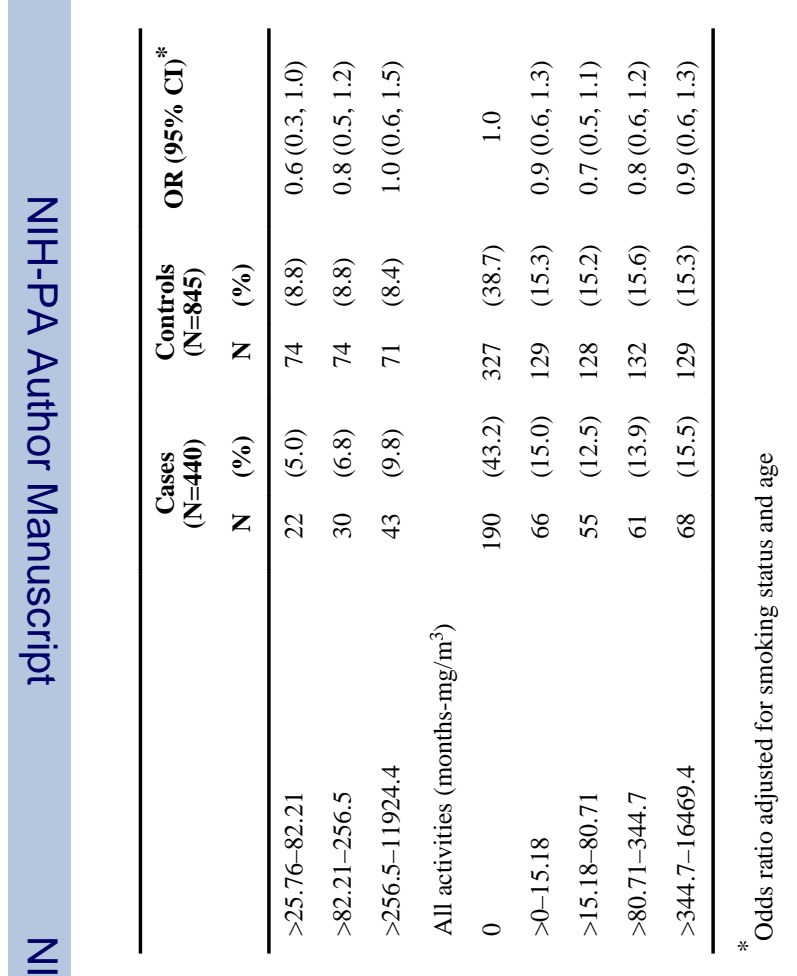

